Bundesgesundheitsbl 2013 · 56:76-86 DOI 10.1007/s00103-012-1590-4

Online publiziert: 19. Dezember 2012

c) Springer-Verlag Berlin Heidelberg 2012
S. Grund ${ }^{1} \cdot 0$. Wichmann $^{2} \cdot$ T. Mertens $^{3} \cdot H$. Hengel ${ }^{1}$

${ }^{1}$ Institut für Virologie, Heinrich-Heine-Universität Düsseldorf

2 Fachgebiet Impfprävention, Robert Koch-Institut, Berlin

${ }^{3}$ Institut für Virologie, Universität UIm

\title{
Konzepte, Wirksamkeit und Perspektiven pandemischer und nichtpandemischer Influenzaimpfungen
}

Seit Jahrzehnten wird gegen die jährlich wiederkehrende saisonale Influenza als der wichtigsten und zugleich impfpräventablen viralen respiratorischen Infektion geimpft. Im Jahr 2009 war erstmalig in der Geschichte der Menschheit die Möglichkeit gegeben, den Verlauf einer Influenzapandemie durch die rechtzeitige Gabe pandemischer Impfstoffe $\mathrm{zu}$ beeinflussen. In diesem Beitrag sollen die Konzepte der saisonalen und pandemischen Influenzaimpfung miteinander verglichen und die vorhandene Evidenz für ihre Immunogenität und klinische Wirksamkeit dargelegt werden. Darüber hinaus soll ein Überblick über die Impfstoffkandidaten gegeben werden, die sich aktuell in der Entwicklung zur pandemischen sowie saisonalen Anwendung befinden, eine verbesserte klinische Wirksamkeit zeigen und schneller verfügbar sein könnten. Zusätzlich wird in einem kurzen Abschnitt der spezifische Aspekt der Impfstoffsicherheit adressiert.

\section{Ziele der saisonalen und pandemischen Influenzaimpfung}

Prinzipiell verfolgen eine saisonale und eine pandemische Influenzaimpfung dasselbe Ziel: die Senkung der influenzabedingten Morbidität und Mortalität sowie der hiermit verbundenen direkten (Arztbesuche, Hospitalisierungen, Antibiotikagaben) und indirekten (Fehltage in der Schule und bei der Arbeit) Krankheitskosten $[1,2]$. Die Impfung während einer Pandemie zielt zusätzlich darauf, die Versorgung Erkrankter und die Aufrechterhaltung essenzieller, öffentlicher Dienstleistungen sicherzustellen [3]. Diese Ziele können über den direkten Schutz der geimpften Personen und auch über den indirekten Schutz von Ungeimpften erreicht werden, da Letztere durch eine im Rahmen der Impfung erzeugte Herdenimmunität weniger mit dem Erreger in Kontakt kommen [4] bzw. wenn es bei der Impfung Schwangerer zu einer Übertragung maternaler Antikörpern auf das Kind kommt [5]. Die Impfung kann insofern einerseits dem Schutz der geimpften Personen und andererseits der Verhinderung einer Transmission des Erregers auf vulnerable Kontaktpersonen dienen, einschließlich solcher Personen, die nicht unmittelbar durch Impfung geschützt werden können.

Primäres Ziel der saisonalen Influenzaimpfung in Deutschland ist der Schutz von Personen, die ein erhöhtes Risiko für einen schweren klinischen Verlauf der Influenza haben (s. unten). Da die saisonale Influenza bei gesunden Erwachsenen in der Regel klinisch relativ mild verläuft, empfiehlt die Ständige Impfkommission am Robert Koch-Institut (STIKO) die Impfung nicht generell für alle Personen [6].

\section{Feststellung eines Impferfolgs: Klinische Endpunkte vs. immunologische Surrogatmarker}

Die Wirksamkeit jeder Impfung muss prinzipiell daran gemessen werden, inwieweit durch die spezifische Interventionsmaßnahme klinisch definierte Endpunkte (z. B. Reduzierung von Hospitalisierung und Mortalität) erreicht werden. Studien mit klinischen Endpunkten wird deshalb eine höhere Evidenz zugemessen als Untersuchungen, die den Impferfolg indirekt anhand immunologischer Surrogatmarker wie Antikörperbestimmungen (z. B. mittels Hämagglutinationshemmtest, $\mathrm{HAH}$; oder Neutralisationstest, NT) definieren. Epidemiologische Beobachtungsstudien (z. B. Fall-Kontroll-Studien oder Kohortenstudien) können die Wirksamkeit einer Impfung nach breiter Anwendung in der Bevölkerung untersuchen (sog. Post-Marketingstudien). Die Wirksamkeit „im Feld“ kann sich von der unter optimalen Studienbedingungen mit selektierten (insbesondere gesunden) Probanden in randomisierten klinischen (Zulassungs-)Studien („randomised clinical trials“, RCT) ermittelten Wirksamkeit unterscheiden. Beobachtungsstudien können daher zusätzliche Evidenz über den tatsächlichen klinischen Nutzen von Impfungen bieten; allerdings weisen sie ein im Vergleich zu RCTs erhöhtes Risiko für systematische Fehler 
Tab. 1 Charakteristika eines (fiktiven) optimalen Influenzaimpfstoffs

\begin{tabular}{|ll}
\hline Charakteristika & Erreichte Ziele \\
\hline $\begin{array}{l}\text { Subklassen- und Driftvariantenübergreifende } \\
\text { Immunogenität }\end{array}$ & Keine regelmäßige Anpassung erforderlich \\
\hline $\begin{array}{l}\text { Hohe Immunogenität auf zellulärer und humo- } \\
\text { raler Ebene }\end{array}$ & $\begin{array}{l}\text { Wirksamkeit auch bei Kleinkindern, älteren und } \\
\text { immunkompromittierten Personen, einmalige } \\
\text { Impfung ausreichend, gute Impfakzeptanz }\end{array}$ \\
\hline Hohe klinische Wirksamkeit & $\begin{array}{l}\text { Reduzierung klinischer Endpunkte (z. B. Morbi- } \\
\text { dität, Hospitalisierungsrate) }\end{array}$ \\
\hline $\begin{array}{l}\text { Hohe Produktionskapazität und Herstellung } \\
\text { ohne embryonierte Hühnereier oder infektiöse } \\
\text { Zellkulturen }\end{array}$ & $\begin{array}{l}\text { Schnelle Verfügbarkeit einer ausreichenden An- } \\
\text { zahl von Impfdosen, Unabhängigkeit von Eivor- } \\
\text { räten und biologischen Sicherheitsstandards }\end{array}$ \\
\hline Gute lokale und systemische Verträglichkeit & Gute Impfakzeptanz \\
\hline
\end{tabular}

auf [7]. Es werden daher in der englischsprachigen Fachliteratur unterschiedliche Begriffe für die Impfwirksamkeit benutzt: „Effectiveness“ (im Deutschen am ehesten „Effektivität“) für die klinische Wirksamkeit in Beobachtungsstudien und „Efficacy“ (am ehesten „Effizienz", also anders als im Deutschen, in dem das Wort auf das Aufwand-NutzenVerhältnis zielt) für die Wirksamkeit im RCT. Die Begriffe werden leider sowohl in der englischsprachigen als auch der deutschen Fachliteratur nicht einheitlich verwendet. Da die Zulassung von Influenzaimpfstoffen aktuell allein auf Basis von Daten aus Immunogenitätsstudien erfolgen kann, stehen für viele Impfstoffe keine Resultate in Bezug auf klinische Endpunkte aus RCTs zur Verfügung, sodass Beobachtungsstudien oft die einzige Evidenz für die klinische Wirksamkeit liefern.

$\mathrm{Zu}$ Beginn einer Influenzapandemie ist die klinische Wirksamkeit einer Impfung zudem mangels ausreichender Viruszirkulation in der Bevölkerung nicht beurteilbar, sodass in dieser Phase nur entsprechende Daten aus Immunogenitätsstudien zur Verfügung stehen können. Im späteren Verlauf und nach ausreichender Versorgung der Bevölkerung mit dem Impfstoff ist seine Schutzwirkung am besten messbar, wenn definierte klinische Endpunkte (z. B. Hospitalisierung) in einem Kollektiv ausreichend oft auftreten und durch einen objektiven Labornachweis (z. B. Influenzanachweis mittels PCR) einem Influenzavirus spezifisch zugeschrieben werden können. Unspezifische Endpunkte wie „Reduzierung der akuten respiratorischen Erkrankungen“ (ARE) oder der „Influenza- like-illness" (ILI) sind gebräuchlich, aber nur eingeschränkt verwertbar: Der durch Influenzaviren verursachte Anteil an allen respiratorischen Infektionen beträgt während einer saisonalen Influenzawelle bei gesunden Erwachsenen im Durchschnitt lediglich 7-15\% und bei Kindern unter 5 Jahren 6-29\% [8, 9].

Die Frage, inwieweit der am häufigsten bestimmte HAH-Antikörpertiter als serologischer Surrogatmarker für Protektion („correlate of protection“) gegen eine Influenzaerkrankung geeignet ist, wurde vielfach untersucht: Seit Jahrzehnten wird davon ausgegangen, dass eine Protektion ab einem HAH-Titer von 1:40 besteht. Grundlage hierfür ist eine Studie von Hobson et al. [10], bei der gezeigt wurde, dass ein Kollektiv aus freiwilligen Probanden bei Titern zwischen 1:18 und 1:32 nur noch zu 50\% mit einem homologen Virus infizierbar war. In einer kürzlich erschienenen Metaanalyse wurde anhand der vorhandenen Daten zu HAH-Titern und symptomatischen Influenzafällen aus 15 Studien $(5899$ Erwachsene mit 1304 bestätigten Influenzafällen) mittels eines bayerischen „Random-effect-Models“ die Beziehung zwischen HAH-Titer und Seroprotektion berechnet [11]. Es wurden die Ergebnisse von Hobson et al. [10] bestätigt und sowohl für Influenza A als auch B ein signifikanter positiver Zusammenhang zwischen beiden Größen gezeigt. Für Antikörpertiter, die mittels NT ermittelt wurden, konnte gezeigt werden, dass ein NTTiter von 1:160 etwa einem HAH-Titer von 1:40 entspricht [12].

Die Festlegung auf einen protektiven HAH-Titer von 1:40 hielt Einzug in die immunologischen Akzeptanzkriterien, die seitens der europäischen Agentur für Arzneimittel (European Agency for the Evaluation of Medicinal Products, EMA) und der amerikanischen Zulassungsbehörde (Food and Drug Administration, FDA) für die Zulassung von inaktivierten Influenzaimpfstoffen gefordert werden [13]. Einer der entscheidenden Akzeptanzparameter ist, dass nach Impfung mit inaktivierten Vakzinen bei Personen zwischen dem 18. und 60. Lebensjahr eine serologisch gemessene Protektionsrate (Seroprotektionsrate, SPR) von $70 \%$ und bei Impflingen über dem 60 . Lebensjahr von $60 \%$ vorliegen muss.

Zur Evidenz eines protektiven $\mathrm{HAH}-$ Grenztiters von 1:40 muss einschränkend festgestellt werden, dass diese weitgehend auf Daten zur Immunogenität und Wirksamkeit inaktivierter saisonaler Influenzaimpfstoffe basiert. Zudem wurden Bedenken geäußert, dass die Interpretation der genannten Surrogatmarker in Populationen mit vorbestehender Teilimmunität (z. B. Ältere aufgrund früherer Exposition zum Influenzaantigen) problematisch sein könnte [14]. Interessanterweise konnte nachgewiesen werden, dass nach Applikation des abgeschwächten Influenzalebendimpfstoffs (s. unten) im Vergleich zu Totimpfstoffen niedrigere HAH-Titer gemessen werden und hierbei vermutlich das Ausmaß der Protektion durch mukosales, schützendes IgA und durch die T-Zell-Immunität unterschätzt wird $[15,16]$. Bei den gängigen serologischen Bestimmungen des Impferfolgs findet der protektive Beitrag des zellulären Immunsystems (z. B. zytotoxischer Lymphozyten) keine Berücksichtigung [17]. In Tierexperimenten konnte gezeigt werden, dass die Applikation des Influenzalebendimpfstoffs in Analogie zur natürlichen Virusinfektion sowohl zur Stimulierung des zellulären Immunsystems auf CD8- (und CD4-)Ebene als auch zur Ausbildung einer humoralen mukosalen Immunität führt und die Versuchstiere hierdurch auch in Abwesenheit neutralisierender Serumantikörper gegen eine homologe Virusinfektion geschützt waren [18]. Auch in Impfstudien an Menschen ließen sich nach Gabe des Lebendimpfstoffs im Vergleich zu Placebo signifikant erhöhte Aktivitätsraten von zytotoxischen $\mathrm{CD}^{+}$-T-Lympho- 
zyten nachweisen [19], während saisonale Totimpfstoffe bei Kindern zu keiner $\mathrm{CD}^{+}$-Immunität gegen Influenza führten [20].

\section{Charakteristika einer (fiktiven) optimalen Influenzavakzine}

In $\bullet$ Tab. 1 sind die Charakteristika einer „optimalen“ Influenzavakzine dargestellt [21]. Im vorliegenden Beitrag soll gezeigt werden, dass die aktuell verfügbaren Impfstoffe einem „idealen“ Influenzaimpfstoff noch nicht entsprechen, sondern Interimslösungen auf dem Weg zu einer noch wirksameren Impfung sind.

\section{Grundannahmen zur saisonalen Influenzaimpfung}

Da aktuell keine Influenzaimpfstoffe verfügbar sind, die eine ausreichend breite Immunogenität und klinische Wirksamkeit gegen verschiedene Virussubtypen und -driftvarianten aufweisen, wird durch die regelmäßige Anpassung der Vakzine den sich kontinuierlich verändernden Influenzaviren Rechnung getragen. Die klinische Wirksamkeit der Impfung hängt entscheidend von der Übereinstimmung des Impfstamms mit dem zirkulierenden Virusstamm ab [1].

Bei einer saisonalen Influenzawelle kommen jährlich 5-15\% der Bevölkerung mit den zirkulierenden Virusstämmen in Kontakt. Dabei verläuft nur ein kleiner Teil der Infektionen klinisch so schwer, dass eine Hospitalisierung erfolgt und der Erreger diagnostiziert wird $[1,21]$. Bei der saisonalen Impfung besitzen erwachsene Personen daher eine im Laufe des Lebens in individuell unterschiedlichem Ausmaß erworbene immunologische Erfahrung auf T- und B-ZellEbene gegenüber früheren Influenzaviren und gegen die aktuellen Impfviren. Insofern erfolgt bei der Impfung zugleich eine Boosterung und Verbreiterung der vorbestehenden Immunität gegen die im Impfstoff enthaltenen neuen „Driftvarianten“. Aufgrund fehlender immunologischer Erfahrung müssen jungen „ungeprimten“ Kindern deshalb 2 Dosen eines saisonalen Influenzaimpfstoffs gegeben werden, um eine entsprechende Immunantwort zu induzieren [22].

Bundesgesundheitsbl 2013 · 56:76-86 DOI 10.1007/s00103-012-1590-4

(c) Springer-Verlag Berlin Heidelberg 2012

\section{S. Grund $\cdot$ O. Wichmann $\cdot$ T. Mertens $\cdot$ H. Hengel}

\section{Konzepte, Wirksamkeit und Perspektiven pandemischer und nichtpandemischer Influenzaimpfungen}

\section{Zusammenfassung}

Im Jahr 2009 waren zum ersten Mal die Voraussetzungen dafür gegeben, den Verlauf einer Influenzapandemie durch die rechtzeitige Herstellung von Impfstoffen zu beeinflussen. Anders als bei der saisonalen Influenzaimpfung, die auf eine erneute Stimulierung und Erweiterung einer vorbestehenden Immunität zielt, muss ein pandemischer Impfstoff bei immunologisch „naiven“ Individuen immunogen und protektiv sein und zudem mit hoher Produktionsgeschwindigkeit hergestellt werden können. In der vorliegenden Übersicht werden Konzepte für saisonale und pandemische Influenzaimpfstoffe vorgestellt, und es werden ihre Immunogenität und klinische Wirksamkeit diskutiert. In näherer Zukunft wird die saisonale Influenzaimpfung weiterhin auf inaktivierten Spalt- und Untereinheitenimpfstoffen oder auf dem kälteadaptierten Lebendimpfstoff beruhen. Die im Jahr 2009 eingesetzten pandemischen
Impfstoffe gegen das Influenzavirus A (H1N1) 2009 wiesen eine bessere Immunogenität auf als anhand präpandemischer Impfstudien erwartet worden war, jedoch muss der zukünftige Einsatz von AS03-adjuvantierten Impfstoffen aufgrund der eingetretenen Nebenwirkungen infrage gestellt werden. Die bisher vorhandenen saisonalen und pandemischen Influenzaimpfstoffe erfüllen aufgrund der Notwendigkeit, sie regelmäßig anzupassen, und wegen ihrer reduzierten Wirksamkeit in vulnerablen Zielgruppen noch nicht die Kriterien für eine optimale Vakzine. Sie stellen aber wichtige Zwischenlösungen auf dem Weg zu besseren Impfstoffen der Zukunft dar.

Schlüsselwörter Influenzaimpfung · Immunogenität · Klinische Wirksamkeit · Herdenimmunität . Zukünftige Impfstoffe

\section{Concepts, effectiveness, and perspectives of pandemic and seasonal influenza vaccines}

\section{Abstract}

For the first time in history, the conditions to influence the course of an influenza pandemic through vaccination were set during the influenza A H1N1 pandemic in 2009. The specific requirements for pandemic vaccines are to be highly immunogenic in immunologically naive individuals and to be producible quickly in large quantities. In contrast, seasonal influenza vaccines induce a booster response and a broadening of preexisting immunity. In this article the concepts of seasonal and pandemic influenza vaccines and data on their immunogenicity and clinical efficacy are reviewed and discussed. In the upcoming years, seasonal influenza vaccination will continue to be based on inactivated split-virion and subunit vaccines or the live attenuated cold-adapted vaccine. The pandemic vaccines used in 2009 proved to be more immunogen- ic than expected from prepandemic vaccine trials, while the adverse events observed with AS03-adjuvanted vaccines call their future use into question. However, neither seasonal nor pandemic influenza vaccines can be regarded to be an ideal solution, because they have to be frequently adapted to new virus strains and they lack effectiveness in particular risk groups. They can be regarded as interim approaches to highly immunogenic vaccines that hopefully become available in the future. The underlying principles of future vaccines are also presented in this article.

\section{Keywords}

Influenza vaccines · Immunogenicity · Clinical efficacy · Herd immunity · Future influenza vaccines

\section{Die verfügbaren saisonalen Influenzaimpfstoffe}

Die bisher zur Verfügung stehenden Influenzaimpfstoffe sind in $\bullet$ Tab. 2 dargestellt. Die trivalenten Impfstoffe beinhalten Antigene gegen die 3 aktuell zirku- lierenden Virusstämme Influenza A/ H1N1, A/H3N2 und Influenza B. Prinzipiell können die inaktivierten Vakzinen sowohl durch Virusvermehrung im bebrüteten Hühnerei (ca. 90\% der weltweit produzierten Impfstoffmenge) als auch durch Anreicherung in Zellkulturen her- 
Tab. 2 Übersicht über die Impfkonzepte gegen die saisonale und pandemische Influenza

\begin{tabular}{|c|c|c|c|}
\hline & Ursprung & Applikation & $\begin{array}{l}\text { Mögliche Adjuvan- } \\
\text { tien }\end{array}$ \\
\hline Inaktivierte Impfstoffe & \multirow{4}{*}{$\begin{array}{l}\text { Hühnerei oder } \\
\text { Zellkultur }\end{array}$} & \multirow[t]{4}{*}{ Intramuskulär } & \multirow{4}{*}{$\begin{array}{l}\text { Ohne Adjuvans } \\
\text { Aluminiumhydroxid } \\
\text { Öl-in-Wasser-Adju- } \\
\text { vantien }^{\mathrm{a}}\end{array}$} \\
\hline Spaltimpfstoff („split-virion“) & & & \\
\hline Untereinheitenimpfstoff („,subunit") & & & \\
\hline Ganzvirusimpfstoff („,whole virion“) & & & \\
\hline Lebendimpfstoff & \multirow[t]{2}{*}{ Hühnerei } & \multirow[t]{2}{*}{ Intranasal } & \multirow[t]{2}{*}{ Ohne Adjuvans } \\
\hline $\begin{array}{l}\text { "Live attenuated influenza vaccine, } \\
\text { (LAIV)", ,', cold-adapted influenza } \\
\text { vaccine, (CAIV)" }\end{array}$ & & & \\
\hline
\end{tabular}

gestellt werden. Die rechtzeitige Herstellung eines pandemischen, aber auch des saisonalen Influenzaimpfstoffs ist eine wissenschaftliche und logistische Herausforderung. Ihre Teilschritte nehmen, nicht zuletzt auch aufgrund der erforderlichen Bereitstellung einer ausreichenden Menge an embryonierten Eiern, mehrere Monate in Anspruch (• Abb. 1, [23]). Da die meisten Influenzaviren in Hühnereiern nicht effizient vermehrt werden können, erfordert ihre Produktion eine vorherige „Reassortierung“ (Austausch von Gensegmenten) mit einem eiadaptierten Virusisolat. So entsteht ein Virus, das im genetischen Hintergrund des eiadaptierten Stamms die Gensegmente des gewünschten Impfstamms enthält, die für seine immundominanten Oberflächenproteine Hämagglutinin (HA) und Neuraminidase (NA) kodieren. Die weitere Aufarbeitung der angereicherten Viren richtet sich danach, ob ein Spalt-, Untereinheiten- oder Ganzvirusimpfstoff hergestellt wird ( $\bullet$ Abb. 1a). Die auf diese Weise hergestellten Impfstoffe werden unter dem Begriff „Trivalente inaktivierte Vakzine (TIV)“ zusammengefasst.

Das Virus für den intranasal applizierten Influenzalebendimpfstoff (FluMist ${ }^{\oplus}$, Firma MedImmune LLC) wird in einem analogen Verfahren mit einem Virusstamm reassortiert, der durch Passagierung bei $25^{\circ} \mathrm{C}$ „kälteadaptiert“ und hierdurch attenuiert wurde („Live attenuated influenza vaccine“, LAIV; „Cold-adapted influenza vaccine“, CAIV; - Abb. 1b, [24]). Der LAIV-Impfstoff wurde vor 4 Jahrzehnten erstmals in den USA verimpft und wird voraussichtlich für die Influenzasaison 2012/13 in Deutschland unter dem Namen Fluenz ${ }^{\circledast}$ (gleicher Hersteller) verfüg- bar sein. In den USA sind sowohl nicht adjuvantierte TIV- als auch LAIV-Impfstoffe zugelassen und werden ohne Priorisierung als gleichwertig betrachtet [1]. Die LAIV ist allerdings bei Kindern mit chronisch-obstruktiver Lungenerkrankung (COPD), bei Schwangeren und immunkompromittierten Patienten kontraindiziert und in den USA nur für Personen zwischen dem 2. und 59. Lebensjahr zugelassen [1]. In Europa ist Fluenz $z^{\varpi}$ vorerst nur für Personen ab dem 24. Lebensmonat und bis zum vollendeten 18 . Lebensjahr zugelassen.

Das Konzept des Ganzvirusimpfstoffs zur Anwendung gegen die saisonale Influenza wurde sowohl in den USA als auch in Europa weitgehend verlassen. Trivalente inaktivierte Spalt- und Untereinheitenimpfstoffe sind zwar tendenziell etwas weniger immunogen, aber auch weniger reaktogen [25]. Ein Ganzvirusimpfstoff weist im Vergleich zu Spalt- und Untereinheitenimpfstoffen, die auf einem hochreinen Antigengehalt basieren, eine höhere Immunogenität auf, was auf das Vorhandensein interner Virusproteine, zellulärer Lipide der Virushülle und die im Viruspartikel enthaltenen Einzelstrang-RNA zurückgeführt wird [26]. Von Letzterer wurde gezeigt, dass sie als „pathogen-associated molecular pattern“" (PAMP) durch den Toll like receptor 7 (TLR7) erkannt wird, was zu einer verstärkten Aktivierung des angeborenen Immunsystems führt [27]. Eine Zugabe von Adjuvans wird bei den meisten verfügbaren TIV-Impfstoffen nicht vorgenommen; dies könnte zwar das Erreichen der oben genannten Ziele (Boosterung und Verbreiterung der vorbestehenden Immunität) positiv beeinflussen, müsste aber mit einer schlechte- ren lokalen Verträglichkeit erkauft werden [28].

\section{Immunogenität und \\ Wirksamkeit der saisonalen Influenzaimpfung}

Die saisonale Influenzaimpfung ist in Deutschland für Personen (einschließlich Kinder) empfohlen, die ein erhöhtes Risiko für einen schweren Krankheitsverlauf der Influenza (z. B. Pneumonie) bzw. für Hospitalisierungen aufweisen. Dies sind Personen über dem 60. Lebensjahr, Patienten mit chronischen Erkrankungen (COPD, Herz-Kreislauf-Erkrankungen, Diabetes, neurologische Erkrankungen, angeborene und erworbene Immundefekte u. a.) sowie Schwangere [1, 6]. Es liegen aus den letzten 4 Jahrzehnten Daten zur Wirksamkeit der saisonalen Influenzaimpfstoffe in unterschiedlichen Impfkollektiven zum Teil unter Einschluss klinischer Endpunkte vor.

Eine allgemeine Influenzaimpfung gesunder Erwachsener im Alter unter 60 Jahren wird in Deutschland noch nicht, aber in den USA empfohlen. Die Frage der Indikation für die Impfung in dieser Bevölkerungsgruppe wird - trotz der vorhandenen Immunogenität sowohl der TIV als auch der LAIV [16, 21] - aufgrund der Seltenheit klinischer Komplikationen in diesem Kollektiv kontrovers diskutiert: Selbst bei einer hohen Viruszirkulation und guten Übereinstimmung zwischen Impfstamm und zirkulierendem Virusstamm erkranken in dieser Gruppe 2-5\% der Nicht-Geimpften vs. $1 \%$ der Geimpften an einer Influenza, meist mit mildem klinischem Charakter [9]. In den USA wird die Impfung seit der Saison 2010/11 für alle Personen über dem 6. Lebensmonat empfohlen, da Daten vorliegen, die zeigen, dass das seit 2009 zirkulierende Influenzavirus A/ H1N1 insbesondere bei jungen, nichtimmunen Erwachsenen schwerere Verläufe hervorruft als frühere saisonale Influenzaviren, dass Risikofaktoren für schwere Erkrankungsverläufe nach einer Infektion zwar oft vorliegen, aber unbekannt sind und weil der Aspekt einer Herdenimmunität besonders gewichtet wird [1]

Personen über dem 60. Lebensjahr sprechen immunologisch schlechter als 
a Inaktivierte Spalt-, Untereinheiten-und Ganzvirusimpfstoffe

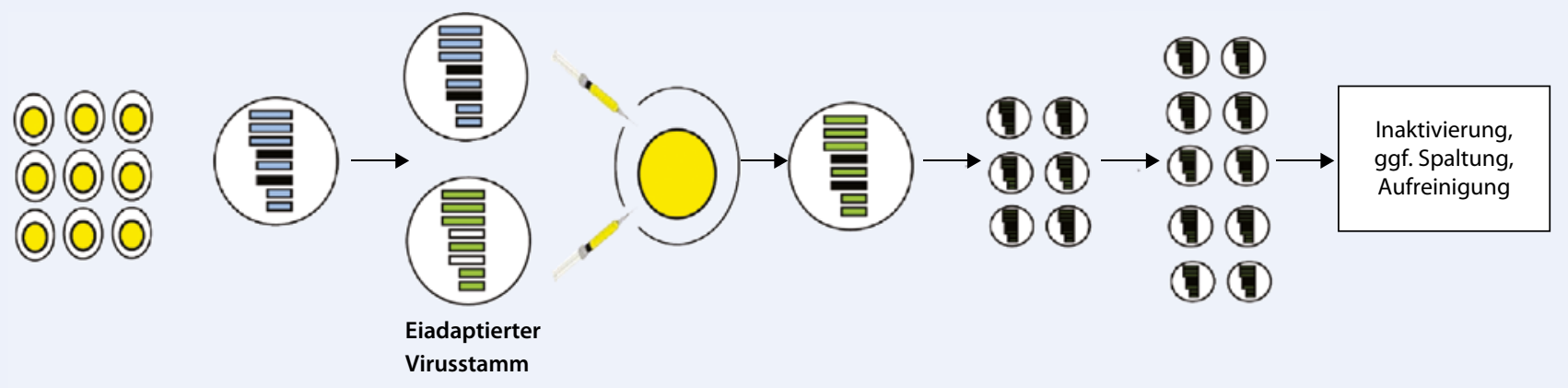

b Kälteadaptierter Lebendimpfstoff

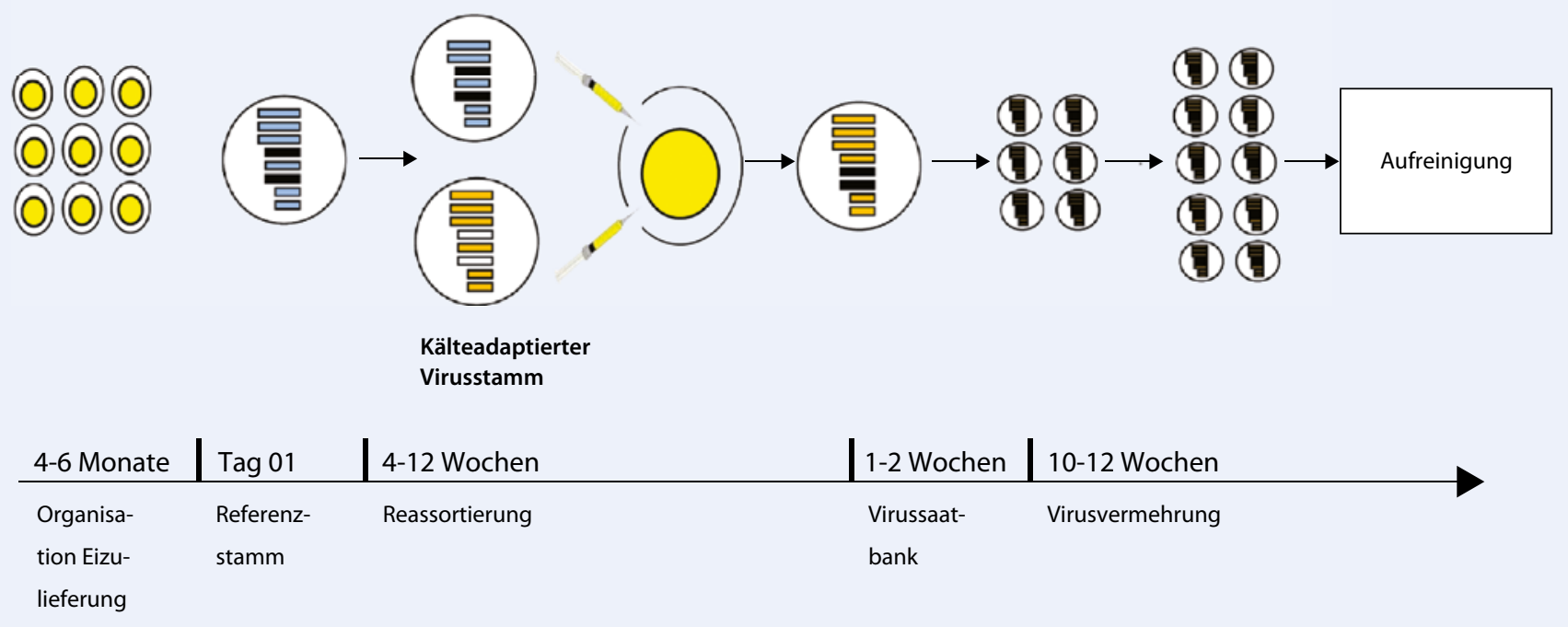

Abb. $1 \Delta$ Herstellungsprozess eibasierter Influenzaimpfstoffe (vereinfachtes Schema)

jüngere Erwachsene auf die Impfstoffe an [29]. Trotz der Tatsache, dass seit mehr als 4 Jahrzehnten gegen Influenza geimpft wird, ist die Datenlage zur klinischen Effektivität der Impfung in dieser Altersgruppe, die traditionell eine Hauptzielgruppe darstellt, inhomogen und basiert größtenteils auf nicht randomisierten Studien. Diese Studien deuten auf eine im Vergleich zu jüngeren Impflingen reduzierte Effektivität ( 73 vs. $58 \%$ bei starker Viruszirkulation und guter Übereinstimmung zwischen epidemischem Virusstamm und Impfstamm) hin [9, 30, 31]. In einer vor Kurzem publizierten Studie konnte bei einer guten Virusstamm/ Impfstamm-Übereinstimmung 2010/11 in den USA eine klinischen Wirksamkeit von 38\% (95\%-KI: -16\%-67\%!) bei Personen $\geq 65$ Jahre nachgewiesen werden [32]. Es findet sich zunehmende Evidenz dafür, dass sich die Immunogenität der
Impfstoffe bei Personen über dem 65. Lebensjahr durch eine Erhöhung des Antigengehalts von $15 \mu \mathrm{g}$ auf $60 \mu \mathrm{g}$ verbessert. Ein entsprechender Impfstoff wurde in den USA zugelassen (Fluzone highdose $^{\oplus}$, Firma Sanofi Pasteur; [1]).

Bei COPD-Patienten gibt es ausreichende Evidenz dafür, dass bei Geimpften vor allem Exazerbationen der chronischen Lungenerkrankung reduziert werden [33]. Schwangere, für die die Impfung seit 2010 in Deutschland empfohlen ist [6], zeigen nach TIV-Impfung ein vergleichbar gutes immunologisches Ansprechen wie andere gesunde Erwachsene, und es gibt keine Hinweise darauf, dass die Impfung eine verminderte klinische Schutzwirkung entfaltet [5]. Limitierte Daten aus einem RCT weisen auf eine klinische Wirksamkeit sowohl bei den Müttern als auch bei den Neugeborenen hin [34].
Bei Kindern bis zum 9. Lebensjahr entspricht die erste Impfung im Leben mangels einer vorbestehenden Immunität häufig einer Erstimmunisierung. Eine 2-malige TIV- oder LAIV-Impfung erbringt in dieser Situation bessere Protektionsraten als eine 1-malige Impfung, selbst wenn im darauffolgenden Jahr ein zweites Mal geimpft wird [22, 35, 36]. In der Altersgruppe der Kinder zwischen dem 6. Lebensmonat und dem 7. Lebensjahr ist die LAIV-Impfung effizienter als die TIV-Impfung [31, 37]. Beide Impfstoffe senken die Rate an klinischen Influenzaerkrankungen und die Fehltage in der Schule. Eine Metaanalyse zeigte jedoch, dass die TIV-Impfung bei Kindern unter 2 Jahren keinen signifikant besseren Effekt mit Blick auf schwere Komplikationen der Influenza wie Pneumonie, Hospitalisierung und Tod hat als Placebo [37]. In randomi- 
sierten klinischen Studien muss untersucht werden, wie diese Bevölkerungsgruppe wirkungsvoll geschützt werden kann (• Tab. 3).

Bei immunkompromittierten Impflingen, bei denen die LAIV-Impfung kontraindiziert ist, zeigen inaktivierte Influenzaimpfstoffe eine verminderte Immunogenität unterschiedlichen Ausmaßes im HAH und NT $[38,39]$. Da die jeweils zugrunde liegenden Erkrankungen und die medikamentöse Immunsuppression variieren, unterscheidet sich das Impfansprechen je nach Kollektiv [8]. Randomisierte Studien mit adäquater Kohortengröße (ausreichende statistische „power") mit klinisch relevanten Endpunkten sind hier bisher kaum vorhanden, sodass die Frage der klinischen Effizienz der Impfung in diesen Fällen weitgehend unklar ist. Die Frage, ob bei Immunkompromittierten eine oder 2 Influenzaimpfungen pro Saison erforderlich sind, wird kontrovers diskutiert [40].

Zusammengefasst liegt das Hauptdilemma der aktuell vorhandenen Influenzaimpfstoffe darin, dass sie zwar bei gesunden Impflingen im mittleren Lebensalter, nicht aber in den vulnerablen Zielgruppen eine zufriedenstellende Immunogenität und klinische Wirksamkeit aufweisen.

\section{Ausgangssituation beim Auftreten der Influenzapandemie im Frühjahr 2009}

Die Influenzapandemien der Jahre 1918/19 („Spanische Grippe“), 1957 („Asiatische Grippe“), 1968 („HongKong-Grippe“) und 1977 („Russische Grippe") haben gezeigt, dass sich ein pandemisches Influenzavirus typischerweise in mehreren Epidemiewellen ausbreiten kann und dass zwischen diesen Wellen mehrere Wochen bis Jahre liegen können [41]. Der die Pandemie im Jahre 2009 auslösende Virusstamm Influenza A (H1N1) wurde im Verlauf der ersten Welle durch die globale Influenza-Surveillance der Weltgesundheitsorganisation (WHO) erfasst und dann auch sequenziert. Da die Herstellung eines neuen Influenzaimpfstoffs, wie bereits oben dargestellt, Zeit braucht, konnte ein Influenza-A (H1N1)-Impfstoff erst vor dem
Höhepunkt einer zweiten möglichen Pandemiewelle zur Verfügung stehen. Zum Zeitpunkt der Identifizierung des pandemischen Influenzavirus im Frühjahr 2009 waren die impfstoffherstellenden Firmen mit der Fabrikation des trivalenten saisonalen Influenzaimpfstoffs für die Wintersaison 2009/10 beschäftigt. Der Produktionsprozess war nach Aussagen der Hersteller bereits so weit fortgeschritten, dass das neue Influenzavirus A/H1N1 (2009) hier nicht mehr berücksichtigt werden konnte [2].

\section{Impfkonzepte während der Influenzapandemie 2009}

Es ist das Wesen einer Influenzapandemie, dass sich ein Virus mit einem neuen HA-Subtyp, gegen das in der menschlichen Population keine oder allenfalls eine geringe Immunität vorhanden ist, verbreiten kann [42]. Anders als bei der saisonalen Influenzaimpfung erfolgen in einer solchen Situation keine Boosterung und Verbreiterung einer vorbestehenden Immunität. Es ist vielmehr das Ziel einer pandemischen Influenzaimpfung, immunologisch „naive“ Individuen im Sinne einer Erstimmunisierung zu „primen“.

Zentral bei einem pandemischen Influenzaimpfstoff ist daher die Frage, wie dieser konfektioniert sein muss, um einerseits bei immunologisch naiven Individuen immunogen, verträglich und sicher zu sein und um andererseits in ausreichender Produktionsgeschwindigkeit hergestellt werden zu können. Die Alternativen, die hierfür im Frühjahr 2009 zur Verfügung standen, werden in den folgenden Abschnitten dargestellt (- Tab. 2).

\section{Nicht adjuvantierte Spalt- und Untereinheitenimpfstoffe, Ganzvirusimpfstoffe und Adjuvantierung mit Aluminiumhydroxid}

Bereits vor 2009 waren Impfstudien mit Impfstoffen auf Basis des aviären Influenzavirus A/H5N1 durchgeführt worden, das als möglicher zukünftiger Pandemieerreger betrachtet wurde $[43,44]$. Dieses Virus verursacht bei wild lebenden Vögeln und beim Nutzgeflügel ausgedehnte Epidemien, infiziert Menschen aber nur sporadisch, sodass sie im Allgemeinen keine vorbestehende Immunität gegen das Virus aufweisen [45]. Es wurde in diesen Studien deutlich, dass entsprechende Spalt- und Untereinheitenimpfstoffe ohne Adjuvans oder adjuvantiert mit Aluminiumhydroxid bei gesunden Probanden (selbst bei hohen Antigendosierungen bis $90 \mu \mathrm{g}$ ) die oben genannten immunologischen Akzeptanzkriterien nicht erfüllten [46]. Als Erfolg versprechender erwiesen sich die zur Impfung gegen die saisonale Influenza bereits aufgegebenen Ganzvirusimpfstoffe. Mit ihnen konnte bei einer Antigendosis von 7,5 $\mu \mathrm{g}$ zwar nicht nach 1-maliger, aber doch nach 2-maliger Impfung eine zufriedenstellende Seroprotektionsrate erzielt werden [25].

\section{Spalt- und Untereinheitenimpfstof- fe mit Öl-in-Wasser-Adjuvantien}

Schon vor der Pandemie 2009 war gezeigt worden, dass die Immunogenität von Influenza-Spalt- und Untereinheitenimpfstoffen durch den Zusatz einer im Vergleich zum Aluminiumhydroxid neueren Generation von Wirkungsverstärkern, sog. Öl-in-Wasser-Adjuvantien [z. B. AS03 der Firma Glaxo Smith Kline (GSK), AF03 der Firma Sanofi Pasteur, MF59 der Firma Novartis], gesteigert werden kann. In präpandemischen H5N1-Impfstudien waren die NT- und HAH-Titer bei gesunden Probanden 3 Wochen nach der ersten und 3 Wochen nach der zweiten Impfung signifikant höher als bei Impflingen, die mit einer nicht adjuvantierten Vakzine gleichen Antigengehalts geimpft worden waren (bis zu 24-fach; [43]). Mit diesen Impfstoffen wurden zudem die immunologischen Akzeptanzkriterien nach 2-maliger Impfung auch bei einem reduzierten Antigengehalt von 3,75 $\mu$ g erfüllt (produktionstechnisch erwünscht, da das Produktionsvolumen auf diese Art erhöht werden kann).

Die genannten serologischen Ansprechraten beziehen sich auf die Frage, inwieweit Serumproben geimpfter Personen gegenüber einem homologen, $d$. h. gegenüber einem dem Impfstamm entsprechenden Virus im HAH oder NT reagieren. Die Impfstoffe wiesen darüber hinaus - im Vergleich zu früheren Vakzinen - eine breitere Immunantwort gegen 
Tab. 3 Ausgewählte Aspekte der Influenzavakzinologie, bei denen ein Mangel an Evidenz vorliegt

Das Ausmaß der natürlichen Viruszirkulation und die Bedeutung der Übereinstimmung zwischen zirkulierendem Virusstamm und Impfstamm wurden in bisherigen Studien oft vernachlässigt.

Insbesondere bei den vulnerablen Zielgruppen mangelt es an randomisierten klinischen Studien adäquater Kohortengröße, die Impfstoffe untereinander ("head-to head“) bzw. gegen Placebo vergleichen (ethisch schwierig durchführbar).

Es mangelt an Studien, die bei ansonsten gleicher Impfstoffzusammensetzung die Immunogenität von Adjuvantien untereinander vergleichen, und auch an Studien, die die Wirksamkeit gegen klinische Endpunkte unter Verwendung eines Adjuvans im Vergleich zu kein Adjuvans belegen.

Es liegen vor allem bei den Risikokollektiven wenige Studien zur Immunogenität und klinischen Wirksamkeit von Mehrdosenimpfschemata vor.

Tendenziell wurden im Vergleich zu Studien, die serologische Surrogotmarker bestimmen, zu wenige Studien zu klinisch relevanten Endpunkten durchgeführt.

Es liegt kaum Evidenz zur klinischen Wirksamkeit der Influenzaimpfstoffe bei Kindern unter 2 Jahren vor.

In Humanstudien wurde nach Applikation des attenuierten Lebendimpfstoffs der Anteil der zellulären und mukosalen Immunität gegen Influenza tendenziell zu wenig untersucht.

Es mangelt an routinetauglichen Labormethoden zur Feststellung des Impferfolgs, die die Funktion des zellulären Immunsystems einbeziehen.

Die Frage, ob ein „priming“ immunologisch naiver Individuen mit dem Lebendimpfstoff und der hiermit verbundenen Stimulierung des angeborenen Immunsystems konzeptionell einer Erstimmunisierung mit einem (ggf. adjuvantierten) Totimpfstoff überlegen ist, muss stärker adressiert werden.

Die klinische Wirksamkeit und subtypenübergreifende Immunogenität zukünftiger rekombinanter Vakzinen muss in humanen Impfstudien ermittelt werden.

veränderte Virusvarianten auf: In einer Studie von Carter und Plosker [43] waren in Serumproben von Impflingen, die gegen einen Influenza-A/H5N1-Virusstamm vom Typ 1 geimpft worden waren, auch seroprotektive Titer gegen einen phylogenetisch und immunologisch abgrenzbaren Virusstamm des Typ 2 nachweisbar. Dieser Effekt ist erwünscht, weil zu Beginn einer Pandemie immer die Befürchtung besteht, dass sich das neue Virus durch die Ausbildung von Driftvarianten rasch antigenetisch diversifizieren könnte.

\section{Abgeschwächter Lebendimpfstoff}

Ein monovalenter pandemischer LAIVImpfstoff gegen das Influenzavirus A (H1N1) - wurde im Oktober 2009 in den USA (FluMist ${ }^{\circ}$, MedImmune LLC), aber nicht in Europa zugelassen. Aufgrund der oben genannten Kontraindikationen für solche Impfstoffe konnte er die parenteral applizierten Totimpfstoffe zwar ergänzen, jedoch nicht ersetzen. Daten zur Wirksamkeit und Sicherheit dieses LAIVImpfstoffs konnten zum Teil aus den Ergebnissen zur Anwendung des saisonalen Lebendimpfstoffs abgeleitet werden; allerdings gab es keine Daten aus präpan- demischen Impfstudien zur Wirkung bei immunologisch naiven Probanden.

\section{USA und Europa: Zwei Impfstoffkonzepte, ein Ergebnis}

In den USA wurden ausschließlich der LAIV-Impfstoff und eibasierte, nicht adjuvantierte Spalt- oder Untereinheitenimpfstoffe zur Impfung gegen das Influenzavirus A/H1N1 (2009) zugelassen. Dies erklärt sich einerseits daraus, dass adjuvantierte Impfstoffe dort nicht rechtzeitig hergestellt und damit zugelassen werden konnten, eine Adjuvantierung der Impfstoffe aber andererseits auch auf Vorbehalte stieß [47]. Der Grund für die bis heute nicht erfolgte Zulassung adjuvantierter (pandemischer und saisonaler) Influenzaimpfstoffen durch die FDA liegt darin, dass in RCTs bislang nicht gezeigt werden konnte, dass die beobachteten höheren Antikörpertiter auch tatsächlich zu einer höheren klinischen Protektionsrate führen.

Anders als in den USA wurden in zahlreichen europäischen Ländern (einschließlich Deutschland) im Wesentlichen Influenza-A (H1N1)-Impfstoffe mit einem reduzierten Antigengehalt $(3,75 \mu \mathrm{g})$, die Öl-in-Wasser-Adjuvantien enthielten, eingesetzt $[2,25]$. Grundlage hierfür war das Prinzip der pandemischen Musterimpfstoffe: Vakzinen, deren Immunogenität und Sicherheit in einer präpandemischen Phase in präklinischen und klinischen Studien mit einem potenziell pandemischen Virusstamm (Influenza A/H5N1, s. oben) belegt worden waren, konnten unter den außergewöhnlichen Bedingungen einer Pandemie in einem beschleunigten Verfahren durch die EMA zugelassen werden $[2,48]$. Es handelte sich hierbei z. B. um sog. „, mock-up vaccines“, bei denen lediglich das HA des H5N1-Virus gegen das HA des pandemischen Influenzavirus A/ H1N1 (2009) ausgetauscht wurde, während alle übrigen Inhaltsstoffe einschließlich Adjuvantien beibehalten wurden. Neben eibasierten Vakzinen kamen in Europa auch die in den USA bisher nicht zugelassenen Zellkulturimpfstoffe zum Einsatz, z. B. der Muster-Ganzvirusimpfstoff Celvapan ${ }^{\circ}$ der Firma Baxter und der neu zugelassene Untereinheitenimpfstoff Celtura ${ }^{\circ}$ der Firma Novartis.

Zwei Jahre nach der Influenzapandemie im Jahr 2009 liegen Daten vor, die auf eine insgesamt gute klinische Wirksamkeit der eingesetzten pandemischen Impfstoffe hindeuten [49]. Es wurden zudem viele Studien zum serologischen Impfansprechen durchgeführt. Sie zeigen das überraschende Ergebnis, dass alle verwendeten inaktivierten Vakzinen eine erheblich höhere Immunogenität aufwiesen, als zu erwarten gewesen wäre. In 2 Metaanalysen wurden die Ergebnisse von 18 RCTs ( $\mathrm{n}>18.000$ Impflinge) unabhängig voneinander zusammengefasst. Beide Analysen kamen zu vergleichbaren Resultaten [50, 51]: In nahezu allen Studien erfüllten alle Spalt- und Untereinheitenimpfstoffe unabhängig von der Antigendosierung und Adjuvantierung in allen Altersgruppen (einschließlich Kinder und Impflinge über dem 65 . Lebensjahr) die immunologischen Akzeptanzkriterien. Bei gesunden Erwachsenen und Jugendlichen wurden auch nach 1-maliger Impfung ausreichende Seroprotektionsraten $(\geq 70 \%)$ erzielt; diese wurden hingegen bei Kindern und Impflingen über dem 65. Lebensjahr nur nach Applikation nicht adjuvantierter Impfstoffe mit einem erhöhten Antigengehalt 

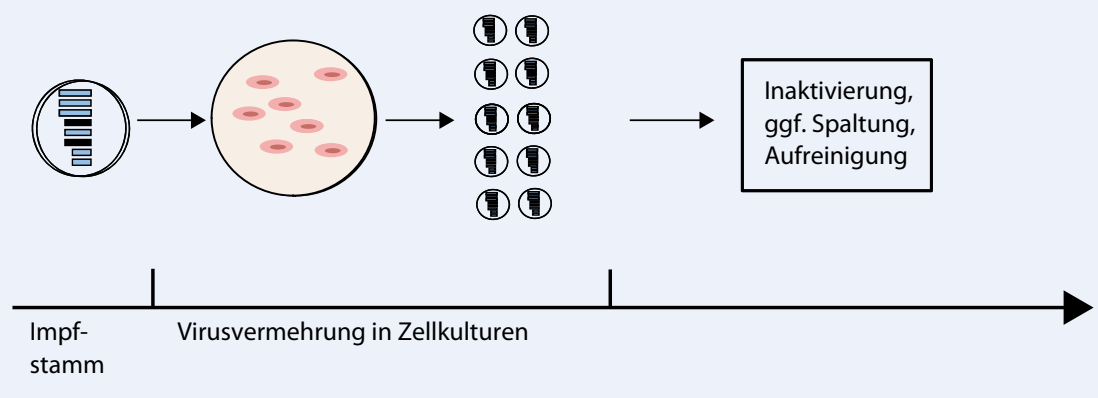

Abb. $2 \Delta$ Herstellungsprozess eines Zellkulturimpfstoffs (vereinfachtes Schema)

a Rekombinantes Protein
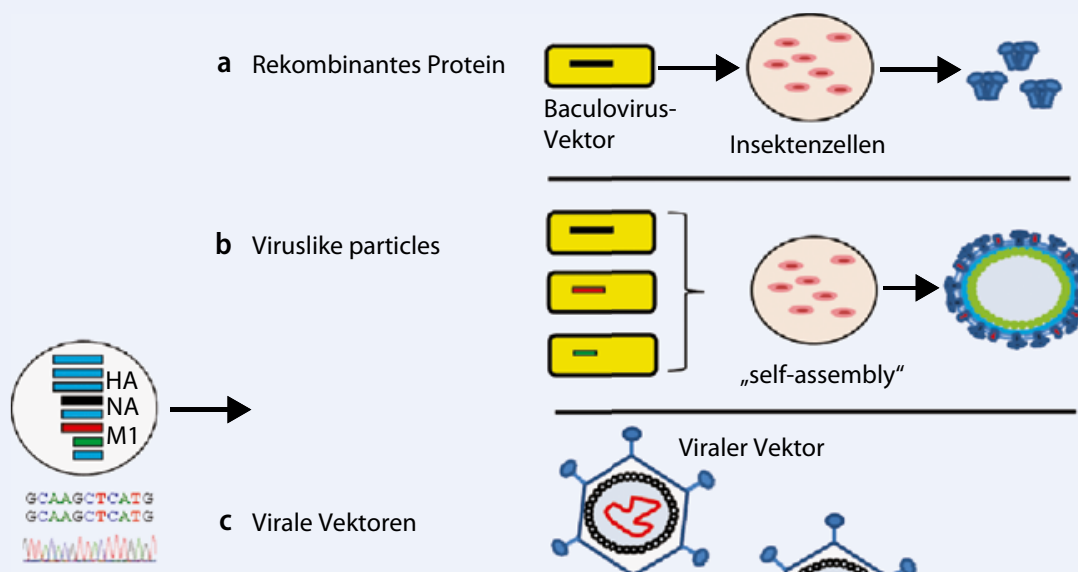

Sequenzierung des Referenzstamms b Viruslike particles
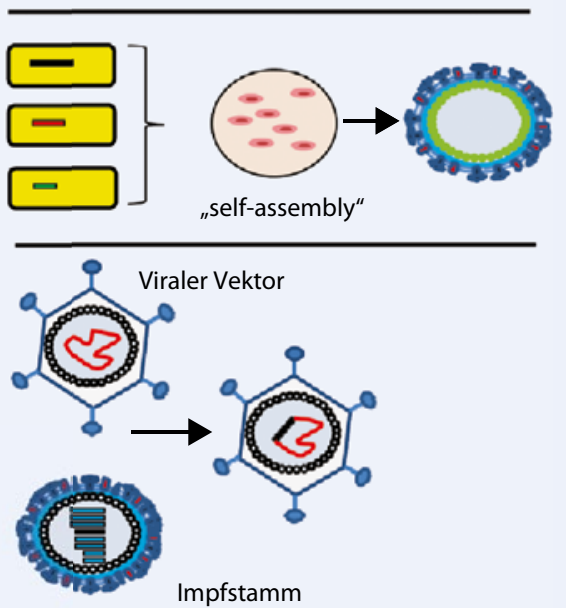

d DNA-Vakzinen

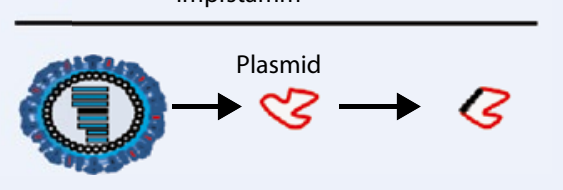

Abb. $3 \Delta$ Konzepte neuer Influenzaimpfstoffe auf Basis rekombinanter Genetik. (Mod. nach [21]; Einzelheiten s. Text)

oder durch Zusatz von Öl-in-Wasser-Adjuvantien (auch bei einer Antigendosierung von $1,88-5,25 \mu \mathrm{g})$ erreicht. Es wurde zudem deutlich, dass vor allem Kinder - anders als Jugendliche, Erwachsene und ältere Impflinge - unabhängig vom verwendeten Impfstoff von einer zweiten Impfung profitierten (Anstieg der Serokonversionsrate um bis zu 37\% im Vergleich zu einer 1-maligen Impfung).

Die in den USA und Europa verwendeten Impfstoffe besaßen eine hohe Immunogenität, sodass trotz der unterschiedlichen Impfstrategien aus immunologischer Sicht in beiden Regionen ähnliche Impfergebnisse erzielt wurden. Bei Erwachsenen wird als Ursache hier- für das anfangs unerwartet hohe Ausmaß einer vorbestehenden Kreuzimmunität angenommen, das die Impfantwort im Sinne eines Boostereffekts begünstigt haben könnte [52]. Zusätzlich wird eine höhere Immunogenität des HA des Influenzavirus A/H1N1 (2009) diskutiert, die das Impfansprechen bei immunologisch naiven Kindern verbessert haben könnte $[25,50]$. Die Frage, ob in einem anderen Pandemieszenario eine der beiden Impfstoffstrategien der anderen überlegen gewesen wäre, kann man also auf Basis der Erfahrung aus der Influenzapandemie 2009 nicht beantworten.

Die in den USA eingesetzte LAIVImpfung zeigte in 2 RCTs bei gesunden
Erwachsenen und Kindern eine geringe Immunogenität (Serokonversionsrate $<30 \%$ im HAH; [53]), wobei die Rate an klinischem Schutz, wie bereits oben dargestellt, vermutlich unterschätzt wird.

\section{Induktion einer Herdenimmunität}

Ziel einer Influenzaimpfung kann es nicht nur sein, die influenzabedingte Morbidität und Mortalität zu senken, sondern auch die Viruszirkulation durch die Induktion einer Herdenimmunität zu reduzieren [2]. Dieser Aspekt wird in den USA (und zum Teil auch in Deutschland) seit Längerem in den Impfempfehlungen berücksichtigt, d. h., dort wird die Impfung auch für Zielgruppen empfohlen, die selbst kein erhöhtes Risiko für einen schweren Erkrankungsverlauf haben, jedoch Personen mit einem erhöhten Risiko betreuen [z. B. Eltern, medizinisches Personal, Kindergärtner(innen) und Lehrer(innen) [8]]. Dieses Vorgehen ist sinnvoll, weil die Impfung bei den zu schützenden vulnerablen Zielgruppen selbst (z. B. bei Personen über dem 60. Lebensjahr) weniger effektiv ist [29].

Zur TIV-Impfung liegen Daten aus RCTs vor, die belegen, dass eine Impfung von Kindergartenkindern die Rate an akuten respiratorischen Erkrankungen bei anderen Familienmitgliedern reduziert [54]. In einer kanadische Studie fand sich ein signifikanter Herdeneffekt nach der TIV-Impfung von Kindern und Jugendlichen: In ländlichen Kommunen, in denen geimpft wurde (Impfabdeckung 83\%), ging die Rate an laborbestätigten Influenzafällen - im Vergleich zu Kommunen ohne Impfung - auch bei den ungeimpften Erwachsenen von 7,6\% auf $3,1 \%$ zurück ( $p=0,03 ;[55])$. Es fehlen bisher allerdings valide klinische Daten darüber, wie hoch die Impfabdeckung zur Induktion einer Herdenimmunität in einer Bevölkerung sein muss und welche Impfquote (in unterschiedlichen Zielgruppen) am kosteneffektivsten und epidemiologisch am sinnvollsten ist [4].

\section{Sicherheit und Verträglichkeit von Influenzaimpfstoffen}

Wie bei vielen anderen parenteralen Impfstoffen kommt es auch nach Appli- 
kation des TIV-Impfstoffes gelegentlich zu Lokal- und Allgemeinreaktionen (lokaler Schmerz, Rötung, Schwellung, Fieber, Abgeschlagenheit, Muskel- und Gelenkschmerzen) als Ausdruck der natürlichen Auseinandersetzung des Organismus mit dem Impfstoff. Diese Beschwerden klingen in der Regel innerhalb weniger Tage folgenlos ab. Meldungen über unerwünschte Wirkungen von Impfstoffen, die über das normale Ausmaß dieser Impfreaktion hinausgehen, werden in Deutschland durch das PaulEhrlich-Institut (PEI) in einer Datenbank über unerwünschte Arzneimittelwirkungen (UAW) erfasst und nachverfolgt (Pharmakovigilanz; [56]). Zudem wird die Sicherheit von Impfstoffen auf Grundlage der vorhandenen Studienlage und der UAW-Meldungen international durch die WHO und national unter anderem durch die Ständige Impfkommission (STIKO) zusammengefasst [57, 58]. In Übereinstimmung mit weiteren Übersichtsarbeiten zu diesem Thema [9] ist festzustellen, dass schwere Nebenwirkungen bei den aktuell verfügbaren saisonalen Influenzaimpfstoffen sehr selten sind und die Vorteile der Impfung überwiegen. Sehr selten kann es zu allergischen Reaktionen der Haut und des Bronchialsystems kommen. Bei Patienten mit einer Allergie gegen Hühnereiweiß sind Influenzaimpfstoffe, die in embryonierten Hühnereiern hergestellt wurden (also die überwiegende Anzahl), kontraindiziert.

Bei dem im Jahr 1976 in den USA eingesetzten Impfstoff gegen die Schweineinfluenza konnte ein erhöhtes Risiko für das Auftreten des Guillain-Barré-Syndroms (GBS) nachgewiesen werden. Die durch die Impfung verursachte Rate an zusätzlichen GBS-Erkrankungen lag bei unter 10 Fällen pro 1 Mio. Impfungen [59]. Für die aktuell verwendeten TIV-Impfstoffe ist ein erhöhtes GBS-Risiko nicht zweifelsfrei belegt. Es liegt laut Studienlage höchstens bei einem Wert von weniger als $2 \mathrm{zu}$ sätzlichen GBS-Fällen pro 1 Mio. Impfungen und damit deutlich unter dem Risiko für einen schweren Erkrankungsverlauf nach einer Influenzainfektion $[9,58]$. Auch ein kausaler Zusammenhang zwischen Influenzaimpfungen und demyelinisierenden Erkrankungen des zentralen
Nervensystems (z. B. Multiple Sklerose) konnte bisher nicht belegt werden.

Seit August 2010 wurde in 3 nordeuropäischen Ländern (Finnland, Schweden, Island) über eine erhöhte Rate von Narkolepsie bei Kindern und Jugendlichen zwischen dem 4. und 18. Lebensjahr berichtet, die mit dem AS03-adjuvantierten monovalenten Spaltimpfstoff Pandemrix $^{\bullet}$ (Firma Glaxo Smith Kline) gegen die pandemische Influenza A/H1N1 (2009) geimpft worden waren [60]. Epidemiologische Studien in mehreren europäischen Ländern zeigten, dass das Risiko bei dieser Personengruppe in den genannten Ländern im Durchschnitt 13-fach erhöht war, was 3 bis 7 zusätzlichen Erkrankungsfällen pro 100.000 Impfungen entspricht [61]. Trotz des weiterhin positiven Nutzen-Risiko-Verhältnisses von Pandemrix ${ }^{\circ}$ empfahl die EMA, diesen Impfstoff nur noch dann bei Personen unter dem 20. Lebensjahr einzusetzen, wenn kein nicht-adjuvantierter trivalenter Impfstoff zur Verfügung steht [61]. Die pathophysiologischen Grundlage für den Zusammenhang zwischen Impfung und Narkolepsie ist bisher noch nicht vollständig geklärt. Die erkrankten Impflinge wiesen als gemeinsames Charakteristikum den Gewebe-HLA-Typ HLA$\mathrm{DRB1}^{\star} 1501-\mathrm{DQB1}{ }^{\star} 0602$ auf, weshalb eine multifaktorielle Genese der Erkrankung (Zusammenspiel zwischen Impfung, genetischer Disposition und ggf. weiteren bisher unbekannten Faktoren) diskutiert wird [62]. Umfangreiche Studien müssen den genauen Mechanismus, der dieser Impfkomplikation zugrunde liegt, untersuchen, um die Frage zu klären, ob die Adjuvantierung eines Impfstoffs in dieser Form bei zukünftigen Influenzapandemien weiterhin möglich sein wird. Eine gepoolte Analyse der Ergebnisse von RCTs mit dem MF59-adjuvantierten Influenzaimpfstoff (79.004 geimpfte Probanden) konnte keinen Zusammenhang zwischen der Impfung und dem Auftreten einer Narkolepsie feststellen [63].

In Kanada wurde zudem ein leicht erhöhtes relatives Risiko für die Entwicklung eines GBS nach AS03-adjuvantierter Influenzaimpfung während der Pandemie 2009/10 festgestellt; es entspricht einem attributablen Risiko von ca. 2 GBS-Fällen pro 1 Mio. Impfdosen [64].
Im Gegensatz dazu konnte in England, wo während der Pandemie auch vornehmlich der AS03-adjuvantierte Totimpfstoff zur Anwendung kam, bisher kein erhöhtes Risiko nachgewiesen werden [65].

\section{Perspektive saisonaler und pandemischer Influenzaimpfungen}

In den letzten Jahren wurden die Kapazitäten zur Herstellung von Zellkulturimpfstoffen weltweit ausgebaut, um der im Fall einer Pandemie durch das aviäre Influenzavirus A (H5N1) zu erwartenden limitierten Verfügbarkeit an embryonierten und unter „Specific pathogen-free (SPF)“-Bedingungen erzeugten Eiern vorzubeugen und den Fabrikationsprozess zu beschleunigen (Organisation der Eizulieferung und Reassortantenbildung entfallen, - Abb. 2). Beschränkend wirkt hierbei, dass nicht alle Virusisolate in der Zellkultur anzüchtbar sind, zu ihrer Anzucht teilweise - analog wie bei eibasierten Impfstoffen - auch eine vorherige Reassortantenbildung erforderlich ist, die Ausbeute in der Regel geringer ist als nach einer Vermehrung im embryonierten Hühnerei und pandemische sowie hochpathogene Viren (z. B. hochpathogene aviäre Influenza) nur in Laboratorien vermehrt werden dürfen, die der biologischen Sicherheitsstufe 3 (BSL-3) entsprechen.

In den USA wird ein attenuierter Zellkulturlebendimpfstoff in Phase-2-Studien getestet. Mittelfristig könnte ein intranasaler Lebendimpfstoff hinzukommen, der mittels gezielter Mutationen im Nichtstrukturprotein 1 (NS1), die die virale Replikationsfähigkeit reduziert, attenuiert ist. Präklinische Studien weisen hier auf eine Stimulierung sowohl des humoralen als auch des zellulären Immunsystems hin [66].

Große Hoffnung wird auf gentechnisch erzeugte rekombinante Impfstoffe gesetzt, die die Möglichkeit bieten, unmittelbar nach Verfügbarkeit der Gensequenz eines Influenzavirus unter Umgehung der Anzucht des infektiösen Virusstamms mit der Herstellung zu beginnen [21]: Die Zulassung einer trivalenten Vakzine, bei der rekombinante Hämagglutinine verimpft werden, die 
nach Klonierung der HA-Gensequenz in einen Baculovirus-Vektor von Insektenzellen exprimiert werden, wurde bei der FDA beantragt (• Abb. 3a, [67]). Der in - Abb. 3b dargestellte Impfstoff beruht auf einem ähnlichen Prinzip, wobei sich aber das virale Hämagglutinin (HA), die Neuraminidase (NA) und das Matrixprotein 1 (M1) nach Klonierung in getrennte Vektoren in der Zellkultur spontan (,selfassembly") zu sog. virusähnlichen Partikeln („virus like particles") vereinigen.

- Abb. 1c zeigt das Prinzip einer vektorbasierten Vakzine, bei der das HA nach der Impfung von einem Trägervirus (z. B. von einem Adenovirus) exprimiert wird, das selbst apathogen ist. Die beiden letztgenannten Impfkonzepte und der Einsatz DNA-basierter Vakzinen (• Abb. 3d), werden zurzeit in klinischen Studien der Phasen 1 oder 2 geprüft. Letztere erbrachte im tierexperimentellen Ansatz vielversprechende Ergebnisse, hingegen waren klinische Studien weniger Erfolg versprechend [21].

Eine universale, d. h. subtypen- und driftübergreifende Vakzine ist mittelfristig nicht in Sicht. In präklinischen Studien wiesen Impfstoffe, die eine Immunantwort gegen hochkonservierte Epitope im Nukleoprotein (NP), im M1- oder HA-Protein des Influenzavirus generieren sollten, bei alleiniger Gabe, in Kombination mit Adjuvantien oder bei sequenzieller Applikation mit anderen Impfstoffen, eine breite kreuzreagierende Immunogenität auf [21, 68]. Ob hiermit klinisch eine Protektion generiert wird, ob eine solche über die Varianten des Influenzavirus hinweg besteht, wie lange sie anhält und ob sie auch bei den vulnerablen Zielgruppen erzeugt werden kann, muss in klinischen Studien untersucht werden.

\section{Influenzavakzinologie und Evidenz}

Trotz der Tatsache, dass die Immunogenität und klinische Wirksamkeit von Impfstoffen gegen das Influenzavirus seit vielen Jahrzehnten untersucht wird, bestehen zu wichtigen Fragen ihrer Wirksamkeit unverändert Evidenzlücken, die in - Tab. 3 exemplarisch zusammengefasst sind und den zukünftigen Studienbedarf beschreiben.

\section{Korrespondenzadresse}

\section{Dr. S. Grund}

Institut für Virologie,

Heinrich-Heine-Universität Düsseldorf

Universitätsstr. 1, Geb. 22.21,

40225 Düsseldorf

Sebastian.Grund@med.uni-duesseldorf.de

Interessenkonflikt. Der korrespondierende Autor gibt für sich und seine Koautoren an, dass kein Interessenkonflikt besteht.

\section{Literatur}

1. ACIP (2010) Prevention and control of influenza with vaccines. Recommendations of the Advisory Committee on Immunization Practices (ACIP), 2010. MMWR 59

2. STIKO (2009) Impfung gegen die Neue Influenza A (H1N1). Mitteilung der Ständigen Impfkommission (STIKO) am Robert-Koch-Institut. Epidemiol Bull 41

3. Robert-Koch-Institut (2007) Nationaler Pandemieplan Teil III der Expertengruppe „InfluenzaPandemieplanung". http://www.rki.de/DE/Content/InfAZ/I/Influenza/influenzapandemieplan_ III.html

4. Kim TH, Johnstone J, Loeb M (2011) Vaccine herd effect. Scand Infect Diseases 43:683-689

5. Steinhoff MC, Omer SB, Roy E et al (2010) Influenza immunization in pregnancy - antibody responses in mothers and infants. N Engl J Med 362:1644-1646

6. STIKO (2009) Änderung der Empfehlungen zur Impfung gegen Influenza. Mitteilung der Ständigen Impfkommission (STIKO) am Robert KochInstitut. Epidemiol Bull 31/2010

7. Weinberg GA, Szilagyi PG (2010) Vaccine epidemiology: efficacy, effectiveness, and the translational research roadmap. J Infect Dis 201:16071610

8. ACIP (2009) Prevention and control of seasonal influenza with vaccines. Recommendations of the Advisory Committee on Immunization Practices (ACIP) 2009. MMWR 58

9. Jefferson T, Di Pietrantonj C, Rivetti A et al (2010) Vaccines for preventing influenza in healthy adults. Cochrane Database Syst Rev:CD001269

10. Hobson D, Curry RL, Beare AS, Ward-Gardner A (1972) The role of serum haemagglutination-inhibiting antibody in protection against challenge infection with influenza $A 2$ and $B$ viruses. J Hyg (Lond) 70:767-777

11. Coudeville L, Bailleux F, Riche B et al (2010) Relationship between haemagglutination-inhibiting antibody titres and clinical protection against influenza: development and application of a bayesian random-effects model. BMC Med Res Methodol 10:18

12. Grund $S$, Adams $O$, Wahlisch $S$, Schweiger B (2011) Comparison of hemagglutination inhibition assay, an ELISA-based micro-neutralization assay and colorimetric microneutralization assay to detect antibody responses to vaccination against influenza A H1N1 2009 virus. J Virol Methods 171:369-373
13. CPMP (1997) Committee for Proprietary Medicinal Products (CPMP). The European Agency for the evaluation of medicinal products. Note for guidance on harmonisation of requirements for influenza vaccines

14. Beyer WE, Palache AM, Luchters G et al (2004) Seroprotection rate, mean fold increase, seroconversion rate: Which parameter adequately expresses seroresponse to influenza vaccination? Virus Res 103:125-132

15. Edwards KM, Dupont WD, Westrich MK et al (1994) A randomized controlled trial of coldadapted and inactivated vaccines for the prevention of influenza A disease. J Infect Dis 169:68-76

16. Treanor JJ, Kotloff K, Betts RF et al (1999) Evaluation of trivalent, live, cold-adapted (CAIV-T) and inactivated (TIV) influenza vaccines in prevention of virus infection and illness following challenge of adults with wild-type influenza A (H1N1), A (H3N2), and B viruses. Vaccine 18:899-906

17. Treanor J, Wright PF (2003) Immune correlates of protection against influenza in the human challenge model. Dev Biol (Basel) 115:97104 18. Chen GL, Lau YF, Lamirande EW et al (2011) Seasonal influenza infection and live vaccine prime for a response to the 2009 pandemic H1N1 vaccine. Proceedings of the National Academy of Sciences of the United States of America 108:1140-1145

19. Gorse GJ, Campbell MJ, Otto EE et al (1995) Increased anti-influenza A virus cytotoxic T cell activity following vaccination of the chronically ill elderly with live attenuated or inactivated influenza virus vaccine. J Infect Dis 172:1-10

20. Bodewes R, Fraaij PL, Geelhoed-Mieras MM et al (2011) Annual vaccination against influenza virus hampers development of virus-specific CD8T cell immunity in children. J Virol 85:11995-12000

21. Lambert LC, Fauci AS (2010) Influenza vaccines for the future. N Engl J Med 363:2036-2044

22. Neuzil KM, Jackson LA, Nelson J et al (2006) Immunogenicity and reactogenicity of 1 versus 2 doses of trivalent inactivated influenza vaccine in vaccine-naive 5-8-year-old children. J Infect Dis 194:1032-1039

23. Matthews TM (2006) Egg-based production of influenza vaccine: 30 years of commercial experience. The Bridge National Academy of Engineering 36

24. Maassab HF, Francis T Jr, Davenport FM et al (1969) Laboratory and clinical characteristics of attenuated strains of influenza virus. Bull World Health Organization 41:589-594

25. Pfleiderer M (2010) Pandemic influenza vaccines. Concepts, European mock-up licenses, and acceptance criteria. Bundesgesundheitsbl Gesundheitsforsch Gesundheitsschutz 53:1242-1249

26. Montomoli E, Piccirella S, Khadang B et al (2011) Current adjuvants and new perspectives in vaccine formulation. Expert Rev Vaccines 10:10531061

27. Geeraedts F, Goutagny N, Hornung V et al (2008) Superior immunogenicity of inactivated whole virus $\mathrm{H} 5 \mathrm{~N} 1$ influenza vaccine is primarily controlled by Toll-like receptor signalling. PLoS Pathogens 4:e1000138

28. Cate TR, Kasel JA, Couch RB et al (1977) Clinical trials of bivalent influenza A/New Jersey/76-A/ Victoria/75 vaccines in the elderly. J Infect Dis 136(Suppl):S518-S525

29. Goodwin K, Viboud C, Simonsen L (2006) Antibody response to influenza vaccination in the elderly: a quantitative review. Vaccine 24:1159-1169 
30. Jefferson T, Di Pietrantonj C, Al-Ansary LA et al (2010) Vaccines for preventing influenza in the elderly. Cochrane Database Syst Rev:CD004876

31. Osterholm MT, Kelley NS, Sommer A, Belongia EA (2012) Efficacy and effectiveness of influenza vaccines: a systematic review and meta-analysis. Lancet Infect Dis 12:36-44

32. Treanor JJ, Talbot HK, Ohmit SE et al (2012) Effectiveness of seasonal influenza vaccines in the United States during a season with circulation of all three vaccine strains. Clin Infect Dis

33. Poole P, Chacko EE, Wood-Baker R, Cates CJ (2010) Influenza vaccine for patients with chronic obstructive pulmonary disease. The Cochrane Library

34. Zaman K, Roy E, Arifeen SE et al (2008) Effectiveness of maternal influenza immunization in mothers and infants. N Engl J Med 359:15551564

35. Englund JA, Walter EB, Gbadebo A et al (2006) Immunization with trivalent inactivated influenza vaccine in partially immunized toddlers. Pediatrics 118:e579-e585

36. Vesikari T, Fleming DM, Aristegui JF et al (2006) Safety, efficacy, and effectiveness of cold-adapted influenza vaccine-trivalent against community-acquired, culture-confirmed influenza in young children attending day care. Pediatrics 118:2298-2312

37. Jefferson T, Rivetti A, Harnden A et al (2008) Vaccines for preventing influenza in healthy children. Cochrane Database Syst Rev:CD004879

38. Gueller S, Allwinn R, Mousset S et al (2011) Enhanced immune response after a second dose of an AS03-adjuvanted H1N1 influenza A vaccine in patients after hematopoietic stem cell transplantation. Biol Blood Marrow Transplant 17:15461550

39. Hansen A, Grund S, Hetzel G et al (2012) Noncontrolled trial of monovalent AS03A-adjuvanted vaccine for 2009 pandemic influenza $A(H 1 N 1)$ in long-term dialysis patients and transplant recipients. Am J Kidney Dis 59:471-473

40. Engelhard D, Nagler A, Hardan I et al (1993) Antibody response to a two-dose regimen of influenza vaccine in allogeneic T cell-depleted and autologous BMT recipients. Bone Marrow Transplant 11:1-5

41. Miller MA, Viboud C, Balinska M, Simonsen L (2009) The signature features of influenza pandemics - implications for policy. N Engl J Med 360:2595-2598

42. Hancock K, Veguilla V, Lu X et al (2009) Cross-reactive antibody responses to the 2009 pandemic H1N1 influenza virus. N Engl J Med 361:19451952

43. Carter NJ, Plosker GL (2008) Prepandemic influenza vaccine $\mathrm{H} 5 \mathrm{~N} 1$ (split virion, inactivated, adjuvanted) [Prepandrix]: a review of its use as an active immunization against influenza $A$ subtype H5N1 virus. BioDrugs 22:279-292

44. Perdue ML, Swayne DE (2005) Public health risk from avian influenza viruses. Avian Dis 49:317327

45. Capua I, Alexander DJ (2007) Avian influenza infections in birds - a moving target. Influenza Other Respir Viruses 1:11-18

46. Treanor JJ, Campbell JD, Zangwill KM et al (2006) Safety and immunogenicity of an inactivated subvirion influenza $A$ (H5N1) vaccine. $N$ Engl J Med 354:1343-1351
47. ACIP (2009) Use of influenza A (H1N1) 2009 monovalent vaccine: recommendations of the Advisory Committee on Immunization Practices (ACIP), 2009. MMWR Recommendations and reports: Morbidity and mortality weekly report Recommendations and reports/Centers for Disease Control 58:1-8

48. EMA (2008) Guideline on dossier structure and content fort pandemic influenza vaccine marketing authorisation application. http://www.ema. europa.eu/docs/en_GB/document_library/Scientific_guideline/2009/09/WC500003869.pdf (Revision)

49. WHO (2012) http://www.who.int/vaccine_research/diseases/influenza/flu_trials_tables/en/ index.html

50. Manzoli L, De Vito C, Salanti G et al (2011) Metaanalysis of the immunogenicity and tolerability of pandemic influenza A 2009 (H1N1) vaccines. PloS one 6:e24384

51. Yin JK, Khandaker G, Rashid H et al (2011) Immunogenicity and safety of pandemic influenza A (H1N1) 2009 vaccine: systematic review and meta-analysis. Influenza Other Respir Viruses 5:299-305

52. Garten RJ, Davis CT, Russell CA et al (2009) Antigenic and genetic characteristics of swine-origin 2009A(H1N1) influenza viruses circulating in humans. Science 325:197-201

53. Mallory RM, Malkin E, Ambrose CS et al (2010) Safety and immunogenicity following administration of a live, attenuated monovalent 2009 $\mathrm{H} 1 \mathrm{~N} 1$ influenza vaccine to children and adults in two randomized controlled trials. PloS one 5:e13755

54. Hurwitz ES, Haber M, Chang A et al (2000) Effectiveness of influenza vaccination of day care children in reducing influenza-related morbidity among household contacts. JAMA 284:16771682

55. Loeb M, Russell ML, Moss L et al (2010) Effect of influenza vaccination of children on infection rates in Hutterite communities: a randomized trial. JAMA 303:943-950

56. Paul-Ehrlich-Institut UAW-Datenbank (DB-UAW) http://wwwpeide/cln_227/DE/infos/fachkreise/ pharmakovigilanz/db/db-1/db-1-nodehtml? nnn=true

57. STIKO (2007) Hinweise für Ärzte zum Aufklärungsbedarf über mögliche unerwünschte Wirkungen bei Schutzimpfungen. Epidemiol Bull 25

58. WHO (2000) Supplementary information on vaccine safety. Part 2: Background rates of adverse events following immunization. http:// wwwwhoint/vaccines-documents/DocsPDF00/ www562pdf

59. Hurwitz ES, Schonberger LB, Nelson DB, Holman RC (1981) Guillain-Barre syndrome and the 19781979 influenza vaccine. N Engl J Med 304:15571561

60. Nohynek H, Jokinen J, Partinen M et al (2012) ASO3 adjuvanted AH1N1 vaccine associated with an abrupt increase in the incidence of childhood narcolepsy in Finland. PloS one 7:e33536

61. EMA (2011) European Medicines Agency recommends restricting use of Pandemrix.

62. Partinen M, Saarenpaa-Heikkila O, Ilveskoski I et al (2012) Increased incidence and clinical picture of childhood narcolepsy following the 2009 H1N1 pandemic vaccination campaign in Finland. PloS one 7:e33723
63. Tsai TF, Crucitti A, Nacci P et al (2011) Explorations of clinical trials and pharmacovigilance databases of MF59(R)-adjuvanted influenza vaccines for associated cases of narcolepsy. Scand J Infect Dis 43:702-706

64. De Wals P, Deceuninck G, Toth E et al (2012) Risk of Guillain-Barre syndrome following $\mathrm{H} 1 \mathrm{~N} 1$ influenza vaccination in Quebec. JAMA 308:175-181

65. Andrews N, Stowe J, Al-Shahi Salman R, Miller E (2011) Guillain-Barre syndrome and H1N1 (2009) pandemic influenza vaccination using an $\mathrm{ASO}_{3}$ adjuvanted vaccine in the United Kingdom: selfcontrolled case series. Vaccine 29:7878-7882

66. Wacheck V, Egorov A, Groiss F et al (2010) A novel type of influenza vaccine: safety and immunogenicity of replication-deficient influenza virus created by deletion of the interferon antagonist NS1. $\mathrm{J}$ Infect Dis 201:354-362

67. Treanor JJ, Schiff GM, Hayden FG et al (2007) Safety and immunogenicity of a baculovirus-expressed hemagglutinin influenza vaccine: a randomized controlled trial. JAMA 297:1577-1582

68. Du L, Zhou Y, Jiang S (2010) Research and development of universal influenza vaccines. Microbes Infection/Institut Pasteur 12:280-286 